


\section{Limitantes que enfrentan los productores de papa del departamento de Intibucá, para acceder a un mercado abierto}

José Ramón Coto García

\section{INTRODUCCIÓN}

Honduras es uno de los 189 países que participaron, en la Cumbre del Milenio celebrada en Nueva York en el mes de septiembre del año 2000, entre los acuerdos de la misma se destaca los ocho Objetivos de Desarrollo del Milenio (ODMs) propuestos para ser logrados al 2015. Tomando como referencia dicho marco, la Universidad Nacional Autónoma de Honduras (UNAH), a través de la Maestría en Demografía Social; han diseñado e impartido en la ciudad de La Esperanza, el Diplomado en Objetivos de Desarrollo del Milenio con Énfasis en Análisis Sociodemográfico con el objetivo de formar capacidades teóricas, técnicas y analíticas entre la población local del municipio.

La presente investigación está basada en el objetivo No. ocho de la Declaración del Milenio, fomentar una asociación mundial para el desarrollo y en la meta 12 que se propone desarrollar un sistema comercial y financiero abierto, en tal sentido, se ha desarrollado una investigación sobre el cultivo de la papa abordando los principales problemas que enfrentan los productores de Intibucá para acceder a los mercados globales.

El documento presenta una justificación, planteamiento del problema, objetivos de investigación, contexto general, marco teórico, principales resultados, metodología, conclusiones y recomendaciones.

Para la realización de esta investigación se consultó diversas fuentes secundarias y se hizo visitas al campo en las zonas productoras tanto de Yamayanguila y el municipio de Intibucá, considerados los únicos en el departamento con potencial productivo en el ramo, utilizando como medio de obtención de información el de informantes claves, lo que le da gran importancia y relevancia a los resultados obtenidos en la investigación desde su inicio hasta su finalización.

\section{JUSTIFICACIÓN}

En las últimos veinte años Intibucá se ha convertido en un departamento con alto porcentaje de emigración de su población especialmente de los jóvenes que salen de sus comunidades remotas a grandes haciendas en tiempos de cosecha de café y zafra de caña; y las mujeres a las maquilas en el norte de Honduras y hacia los Estados Unidos, España y otros países.

Este departamento de Intibucá, cuya tierra alberga a los indígenas lencas, es una zona de gran importancia en la producción de papa, en la actualidad el cultivo del tubérculo se ha vuelto más crítico debido al abandono en el que continúan inmersos los productores.

Las frecuentes quejas de los productores Intibucanos de papa, en el sentido de mantener una deuda con la banca privada nacional que supera los 35 millones de lempiras aproximadamente, indicando que se ha debido a la pésima calidad de la semilla y el mal manejo del transporte de esta por importadores y distribuidores en la zona, señalan en este hecho la causa de sus pérdidas, así mismo expresan que el gobierno carece de una política definida, en materia de producción ya que su intervención es de tipo aislado a manera de proyectos pilotos y no le dan continuidad a los mismos. 
Por su parte el gobierno en el año 2007 anuncio un plan de reactivación, por medio de la Secretaría de Agricultura y Ganadería (SAG) y Dirección de Ciencia y Tecnología Agropecuaria (DICTA), en apoyo a la producción de papa y otros cultivos. El plan pretende ejecutar gradualmente la gestión de financiamiento, asistencia técnica, fortalecimiento de la organización, comercialización, capacitación, industrialización, preparación post cosecha y valor agregado. La capacitación a los productores está orientada en talleres sobre botánica del cultivo, producción artesanal, almacenamiento de semilla de papa y manejo integrado de plagas y enfermedades que afectan en la zona, así como la identificación y seguimiento de la cadena productiva del cultivo. (SAG 2007).

Los Lencas se dedican en su mayoría al cultivo de la papa, rotándolo con granos básicos y algunas hortalizas, todos los miembros de la familia se involucran con las labores de cultivo, como siembra y cosecha. A pesar, que el departamento posee condiciones favorables competitivas para producir dicho cultivo, no sólo para el consumo nacional, sino para mercados externos, esto no ha sido posible debido a que los volúmenes producidos no alcanzan ni para suplir el mercado nacional. Precisamente este es un elemento esencial en la investigación, que nos permitirá conocer e identificar las principales causas que impide a los productores de papa acceder a mercados internacionales de papa producida a nivel nacional.

\section{PLANTEAMIENTO DEL PROBLEMA}

Para el grupo indígena Lenca dedicado al cultivo de la papa, ha sido muy difícil alcanzar grandes resultados, no sólo en volumen, sino en calidad; primeramente por falta de disponibilidad de semilla de calidad, ataque de plagas epidémicas, financiamiento para la producción, alto endeudamiento, poca asistencia técnica, deficiente comercialización, falta de industrialización y valor agregado a sus productos, esta es una de las razones que inspira investigar cuáles son las limitantes que enfrentan los productores de papa para adherirse a mercados abiertos, ya que es un cultivo que ha tomado gran importancia en el plano alimenticio y como alternativa para sustituir otros alimentos que ya no están al alcance de las personas en diversas partes del mundo incluyendo América Latina.

\section{OBJETIVOS}

\subsection{General}

- Describir las diferentes limitantes que enfrentan los productores de papa de Intibucá, para acceder a un mercado abierto.

\subsection{Objetivos específicos}

- Identificar las principales causas que impide a los productores de papa acceder a mercados internacionales.

- Enumerar algunas enfermedades e insectos que dañan el cultivo de la papa, para que sean tomados en cuenta por los productores de la misma.

- Investigar los diferentes requisitos requeridos por los mercados abiertos, para realizar exportaciones e importaciones.

\section{CONTEXTO GENERAL}

La papa es sin duda un cultivo que ha despertado el interés a nivel mundial en el siglo XXI, ya que Naciones Unidas ha declarado el 2008 como año internacional de la papa, esto quizá por la fuerte crisis mundial de alimentos que afecta en mayor escala a los países en vías de desarrollo.

La papa cuyo nombre científico es "Solanum Tuberosum”, al principio se dijo que era un poderoso afrodisíaco, seguidamente se aseguró que sólo servía de alimento a los animales, ya que por salir de la profundidad de la tierra, traía algo del infierno y la convertía en una toxina o veneno y era un medio de transferir la lepra una enfermedad muy temida por los humanos en ese tiempo, luego que se produjeron las guerras y que dejaron como consecuencia las hambrunas esto en el siglo XVIII y las personas descubrieron que la papa significaba la diferencia entre la inanición y la vida, convirtiéndose desde esa época en un alimento indispensable en la dieta alimenticia de las personas. 
Cientos de millones de personas en los países en desarrollo están enfrentando una crisis debido al aumento de precios de los alimentos de primera necesidad. El precio del arroz prácticamente se ha duplicado en lo que va del 2008 y el trigo también ha subido de precio rápidamente. Pero el precio de la papa permanece estable, a pesar de ser el tercer cultivo alimentario más importante del mundo.

La papa tiene el potencial de aliviar la presión de los incrementos de precios de los cereales entre las personas más pobres y contribuir significativamente a la seguridad alimentaria según los especialistas del Centro Internacional de la Papa (CIP). En efecto, la papa es un cultivo sembrado y consumido localmente, con un comercio internacional significativamente pequeño en comparación con los cereales, por lo que constituye un alimento particularmente valioso para los países en desarrollo.

Hoy, cientos de millones de personas en los países en desarrollo dependen de las papas, afirma la Dra. Pamela K. Anderson, Directora General del Centro Internacional de la Papa (CIP) quien manifestó que las poblaciones de África, Asia y Oceanía consumen más de 113 millones de toneladas de papas por año. Muchos países en desarrollo están usando la papa para alimentar a sus poblaciones y ayudar a nutrir a los millones que nacen cada año (www. cipotato.org)

Según el CIP, en 2007 la producción mundial del tubérculo alcanzó su récord de 320 millones de toneladas. Más aún la producción en los países en desarrollo casi se ha duplicado desde 1991, con el correspondiente aumento en el consumo. Desde que terminó la guerra en Angola, la producción de papa en ese país aumentó en 1200 por ciento. En Ruanda la producción pasó de menos de 100,000 toneladas en 1961, a aproximadamente 1,3 millones de toneladas en 2007, pero China es el principal productor de papa del mundo, con 72 millones de toneladas, seguido de Rusia, India, Ucrania y los Estados Unidos. Sin embargo, el potencial de la papa todavía no se ha hecho realidad plenamente y nunca había sido tan evidente hasta que el precio del arroz, trigo y maíz sufrieron las alzas recientes. (www.cipotato.org)
Las investigaciones realizadas hasta el momento han mejorado enormemente su productividad, resistencia a enfermedades aumentando los ingresos potenciales, pero se requiere investigación adicional. Mientras los rendimientos promedio de papa en América del Norte y Europa occidental alcanzan a menudo 40 toneladas por hectárea, en los países en desarrollo generalmente están por debajo de las 20 toneladas por hectárea.

La papa está contribuyendo sustancialmente a satisfacer la necesidad de alimentos en los países en desarrollo. Su consumo ha aumentado desde un promedio de $9 \mathrm{Kg}$. por persona en 1961-63 a más de $14 \mathrm{Kg}$. por persona actualmente. El cultivo es fundamental para los regímenes alimentarios de las poblaciones de América del Sur, África, Asia y especialmente Asia central.

La papa tiene muchas ventajas como cultivo comercial y alimentario, produce más nutrición, energía y biomasa comestible por unidad de área y tiempo que otros cultivos esenciales. Las tasas de crecimiento de la papa no sólo se han incrementado sino que han excedido las tasas de crecimiento de muchos otros productos alimenticios de los países en desarrollo en los últimos años.

Los historiadores dedicados al estudio de la papa, han coincidido que es una planta originaria de América, sin determinar con verdadera exactitud que parte de este continente es su centro de origen. En el Compendio y Descripción de las Indias Occidentales, escrita en 1628 ó 1629 por Fray Vázquez de Espinoza, se encuentra la primera relación detallada del cultivo de la papa en América. Las referencias que hace van desde Quito a Ecuador, Perú, Alto Perú (Bolivia), Argentina, Chile y Paraguay, donde llega hasta la ciudad de Castro en la Isla Grande de Chiloé. Se afirma en este trabajo que las papas son mejores que las frutas y esto es mucho decir para un español que esta catalogando un "alimento de indios". Vicente Carballo Goyeneche hace algunos alcances respecto de las variedades que tendrían los indios de estas papas, las hace alcanzar hasta treinta y agrega: "con eso se lo pasan más del año, sin comer carne, porque los carneros los guardan para las fiestas, para cumplir con los parientes y de ordinario tienen 
tan poco ganado que no sufre tanto gasto". (Sitema Informativo Empresarial 2008).

La papa se originó en América del Sur, con todo; esta región es la que menos produce papa en el mundo, menos de 16 millones en 2007. Para la mayoría de los pequeños campesinos de la región andina la papa sigue siendo un cultivo tradicional y se cultiva con otras especies de papa desconocidas en el resto del mundo. En otros países como Argentina, Brasil, Colombia y México; está aumentando la producción comercial a gran escala de Solanum tuberosum, Brasil es el principal productor latinoamericano de papa.

En el caso de Centroamérica, en Guatemala el cultivo de la papa, se realiza en áreas con temperaturas templadas preferentemente menores de $20^{\circ} \mathrm{C}$. En este tipo de clima la papa se desarrolla adecuadamente y se obtiene la mejor productividad, existe poca dificultad con plagas y enfermedades y los tubérculos se desarrollan bien fisiológicamente. Se cuenta con la ventaja que Guatemala posee 17 microclimas que permiten cultivar papa a lo largo de todo el año y las principales variedades sembradas son la Loman, la Tollo can y la Atzimba. La variedad Loman se caracteriza por tener una forma alargada y es de color blanco, mientras que las variedades Tollo can y Atzimba tienen forma redonda y también son de color blanco. Este país se ha posicionado como el principal exportador centroamericano de papa fresca, manteniendo una tendencia creciente cercana al 14\% anual durante los últimos 10 años (Inversiones y Desarrollo de Centroamérica, S.A.1999)

En el caso de Honduras, la región occidental es la zona donde más se produce papa y el departamento de Intibucá el mayor productor. El cultivo de la papa es introducido al municipio de Intibucá por el ingeniero Theodoracopoulos, en la década de los 50, importando la semilla de Holanda de las variedades de alpha, mirka y red póntiac; es así como se inician esfuerzos de comercialización y transferencia de tecnología.

El departamento de Intibucá localizado en la parte occidental tiene una extensión territorial de 3,123 km2 y limites con los departamentos de Santa Bárbara, Coma- yagua, La Paz y la República de El Salvador, la extensión territorial es de $3,123 \mathrm{~km} 2$ y una población estimada al 2008 de 220,048 mil habitantes con una densidad poblacional de 70.4 habitantes por kilómetro cuadrado (INE 2001), dividida políticamente en 17 municipios; su cabecera departamental es la ciudad de La Esperanza, que se encuentra a 188 kilómetros de distancia de Tegucigalpa, capital política del país y a igual distancia de San Pedro Sula. Con la construcción del proyecto del canal seco, esto hace crecer las expectativas para convertirse en una zona con ventajas desde el punto vista estratégico geográficamente para la producción de papa, ya que la distancia en kilómetros, como el tiempo medido en horas se ve reducido una vez concluido el mencionado megaproyecto vial.

Honduras consume 55 mil toneladas métricas de papa al año, hay alrededor de 2,500 productores y se cultivan más de 1,500 manzanas de papa, principalmente en las zonas de Intibucá, Ocotepeque y Francisco Morazán (SAG, 2008), el representante de la Organización de las Naciones Unidas para la Agricultura y la Alimentación (FAO) para Honduras, el señor Compton Paul, informó que la producción nacional es de unas 30,000 toneladas de papa al año, por lo que se hace necesario fortalecer el nivel de producción (La Tribuna, julio 2008).

\section{MARCO TEÓRICO}

\subsection{Tecnología del cultivo}

Las variedades de papa que los productores Intibucanos cultivan son aptas para el consumo de mesa, más no para la industria, cuya demanda no se cubre por falta de variedades apropiadas para la industrialización, siendo abastecida a través de la importación.

Para producir semillas de papa se requiere de todo un proceso, es necesario comenzar con un ingeniero Agrónomo que entienda los problemas sanitarios y fisiológicos que se presentan en las plantas durante el crecimiento en el invernadero y en las diferentes etapas de su desarrollo en el campo; es una actividad continua y de largo plazo, que requiere de una asistencia profesional. Para resolver 
algunos de los problemas que se presentan es necesario hacer algún tipo de investigación.

Para la producción de semilla de papa no se requiere poseer grandes extensiones de tierra. Lo importante es conocer la sanidad de cada lote donde se va a sembrar; con el objeto de no perder un material valioso por contaminación de patógenos del suelo, como Spongospora subterránea (Roña de la papa) y Ralstonia solanacearum (Dormidera) etc.

Si el proyecto comprende el ciclo completo de producción, se requiere de invernadero, campos bien aislados para la siembra de mini tubérculos sanos y bodega para mantener la semilla de las diferentes categorías en condiciones óptimas. La dimensión de una utilización de semillas, como negocio, puede ser de diferente área dependiendo si se dedica a desarrollar todo el proceso de producción partiendo desde el material in Vitro hasta llegar a la semilla certificada o solamente a producir certificada partiendo de categoría básica.

La micro propagación del material in Vitro constituye el punto de partida hacia la producción de una semilla de buena calidad, pero ésta labor es generalmente ejecutada por laboratorios especializados.

Del manejo que se dé a la semilla desde el momento de la cosecha hasta su almacenamiento definitivo, depende en gran parte la conservación de la calidad que se ha conservado durante el proceso de producción.

La semilla debe cosecharse cuando el cultivo haya alcanzado su madurez fisiológica, aquí es muy importante el concepto y experiencia del ingeniero Agrónomo. En el momento de la cosecha siempre se presentan tubérculos con ataques de plagas, enfermedades o defectos fisiológicos que es necesario eliminar.

Es importante contar con personal capacitado, herramientas apropiadas así como condiciones climáticas apropiadas para la cosecha.

Es poco lo que se puede hacer, para mejorar la calidad de la semilla; con un tratamiento a base de productos químicos después de la cosecha. El tratamiento con fungicidas está dirigido al control de hongos que atacan superficialmente la piel como es el caso de Rhizoctonia.
No es aconsejable hacer tratamientos por inmersión en soluciones fungicidas dados el peligro de infecciones por bacterias.

El almacenamiento en forma adecuada es un proceso muy importante, para mantener la calidad de la semilla se debe partir de hecho que el tubérculo-semilla es un tallo modificado que durante su almacenamiento requiere de oxígeno, luz difusa, baja temperatura y adecuada ventilación entre pilas o bultos para prepararse a dar origen a nuevas plantas.

Previo al almacenamiento la bodega debe asearse y desinfectarse con productos químicos para eliminar toda fuente de plagas y enfermedades, cada bulto se debe proteger con un polvo insecticida para evitar los ácidos y polillas que pueden llegar y depositen sus huevos.

\subsection{Propagación en invernadero}

La propagación en invernadero se hace a partir de plántulas in Vitro, tallos o mini tubérculos. Al recibir las plántulas hay que trasplantarlas a camas o a maceteras e iniciar su proceso de adaptación (endurecimiento), proporcionándoles una cámara húmeda a cada una. El suministro de agua debe hacerse preferiblemente con riego por goteo o micro aspersión, el manejo de plaguicidas y fertilizantes debe realizarse con mucho cuidado ya que las raíces de las plántulas son muy sensibles al daño por químicos, cuando estas están en pleno desarrollo, se hace la prueba serológica denominada ELISA, para detectar la presencia de virus.

El aislamiento de lotes es un principio que se debe tomar en cuenta en todo proyecto de semillas. La mejor estrategia es ubicar lotes donde no se haya sembrado papa por varios años, conocer su historia y asegurarse que están libres de problemas fitosanitarios graves que puedan contaminar el material limpio. Las zonas paperas del rastrojo presentan el mejor hábitat para el cultivo de una buena semilla, esta es una práctica hereditaria de los agricultores. Los cultivos de semilla desarrollados en climas con bajas temperaturas van a tener un mayor rendimiento en la próxima cosecha, conociéndose el fenómeno como "Vigor Nórdico". A pesar de que estas 
zonas están siendo vetadas por las autoridades ambientales para el cultivo de papa, a pesar de esto, sigue siendo la mejor alternativa conservar la calidad y potenciar la productividad de la semilla.

\subsection{Comercialización}

Los precios fluctuantes de la papa fresca en el mercado y es que el mayor volumen de la "semilla" que se comercializa se reduce a una papa de consumo de bajo precio en el mercado, que se ha dejado brotar; en cambio la oferta de semilla certificada es muy baja. Este concepto tiene que desvirtuarse demostrando las bondades de una semilla certificada por parte de agricultores que están convencidos de su potencial de rendimiento depende en gran parte de la imagen que tengan del semillerista y la misma se logra demostrando resultados. Los siguientes factores podrían motivar al productor a decidirse a adquirir una semilla certificada:

Conocimiento sobre los rendimientos obtenidos por otros productores.

$\checkmark$ Una oferta oportuna, antes de iniciarse la época de siembras.

$\checkmark$ Mantener en lo posible un precio estable y accesible.

$\checkmark$ Entregar a cada cliente unas recomendaciones básicas para el manejo de cada variedad en el campo.

\subsection{Fisiología y manejo de tubérculos.}

A nivel comercial, la papa se propaga vegetativamente por medio del tubérculo al cual se le da el nombre genérico de semilla; esto permite mantener su constitución genética inalterable, sin embargo, existen otras formas de propagación por medio de semilla sexual o por partes vegetativas como esquejes, brotes y meristemos.

El tubérculo semilla es el órgano responsable de dar origen a una nueva planta y de su calidad depende en gran parte el rendimiento final. El concepto de calidad de semillas incluye tanto el grado de sanidad como su estado fisiológico, por consiguiente; es necesario tomar todas las medidas posibles de protección durante la cosecha, la clasificación y el almacenamiento, con el fin de mantener al máximo el potencial de rendimiento de la semilla.

La semilla es el insumo más importante en cualquier proceso de producción; la condición básica para obtener niveles de productividad elevados es lograr que los tubérculos semilla, alcancen el estado de brotamiento más adecuado al momento de la siembra, por lo tanto, las prácticas de manejo de post cosecha que se realicen con éstos, se deben concentrar en aquellos factores y condiciones que influyen en el desarrollo de brotes vigorosos, que luego dan origen a tallos fuertes y libres de enfermedades. En general, es necesario considerar dos factores estrechamente ligados con la emisión de brotes:

$\checkmark$ La variedad de papa responsable de la duración del período de reposo.

$\checkmark \quad$ La edad fisiológica del tubérculo semilla, la cual depende de las condiciones de almacenamiento a las cuales ha sido sometida la semilla durante el desarrollo fisiológico.

\section{- Estabilidad dormancia}

El período de estabilidad es una característica que depende de la variedad, las papas de las subespecies solanum tuberosum, ssp tuberosum y ssp andigena pasan por un período de relativa inactividad antes de emitir brotes y las papas chauchas o criollas de la subespecie phureja no presentan período de reposo.

La dormancia es el estado durante el cual los tubérculos no brotan, aún bajo condiciones ambientales, que en otras circunstancias serían favorables para un brotamiento rápido, la duración de este período es un factor determinante para definir el momento más oportuno para la siembra. Es importante resaltar el riesgo que significa sembrar tubérculos que no hayan concluido su dormancia, puesto que las plantas pueden emerger en forma irregular con un solo tallo o tubérculos, que se pueden desintegrar en el suelo antes de emerger; ocasionando con ello el fracaso del cultivo.

El período de dormancia termina al iniciarse el crecimiento del primer brote. Para evaluar las diferencias entre variedades de papa, se define este período cuando el $80 \%$ de los tubérculos de una muestra mínima de 20 
tubérculos de tamaño uniforme, han desarrollado uno o más brotes de por lo menos $3 \mathrm{~mm}$. de largo.

El período de dormancia puede ser:

$\checkmark$ Dormancia total: comprendido desde la fecha de inicio de la tuberización en las plantas, hasta el término de la dormancia.

$\checkmark$ Dormancia poscosecha: comprendido desde el momento de la cosecha, hasta el fin de la dormancia.

La duración de ambos períodos la determina el inicio del brotamiento. El concepto de dormancia total es más preciso pero más difícil de determinar y por tal razón, se usa la dormancia post cosecha, para fines prácticos.

El tamaño es un factor que influye en la duración del período de dormancia; los tubérculos pequeños tienen un período más prolongado que los más grandes. Además, los tubérculos pequeños presentan una pérdida de peso más acelerado, porque la superficie por unidad de peso es significativamente mayor.

\section{- Brotamiento surtido}

El estado de brotamiento surtido o múltiple, puede durar varios meses según la variedad, especialmente cuando los tubérculos son almacenados a bajas temperaturas y cuando los tubérculos son almacenados bajo luz difusa, el brotamiento se mantiene con brotes cortos y fuertes, ideales para la siembra. Generalmente este es el estado óptimo para sembrar tubérculos-semillas. Los tubérculos en este estado, originan plantas con varios tallos.

\section{- Envejecimiento}

Luego del período de brotamiento múltiple, el tubérculo envejece, observándose ramificación excesiva de los brotes, formándose brotes largos y débiles y también tubérculos diminutos directamente de los brotes. En este estado, los tubérculos-semillas ya no producen plantas productivas.

La vejez puede ser retardada, produciendo y almacenando tubérculos semillas a temperaturas bajas. Los tubérculos producidos durante una temporada cálida del cultivo, alcanzan el estado de senectud más rápido que los producidos durante una temperatura fría.
Durante su desarrollo fisiológico el tubérculo atraviesa por varios estados, desde el estado de dormancia hasta el de senectud o vejez, ambos extremos son totalmente inadecuados para el uso como semilla. En este proceso llamado también envejecimiento fisiológico, el tubérculo cambia de fisiológicamente joven a fisiológicamente viejo.

La papa se cultiva principalmente a alturas de 1800 a 2300 sobre el nivel del mar.

\subsection{Factores que afectan la duración del período de dormancia}

\section{- La variedad}

La dormancia del tubérculo puede durar menos de un mes o varios, según la variedad. En general, la duración del período no está relacionada con la duración del ciclo vegetativo de una variedad, por ejemplo: en una variedad precoz la duración de la dormancia no es necesariamente corta, además; las variedades reaccionan en forma diferente al ambiente de almacenamiento.

\section{- Condiciones de crecimiento}

Las condiciones en las cuales se producen los tubérculos-semillas afectan la duración del período de dormancia, por ejemplo: las temperaturas altas, el bajo contenido de humedad y la baja fertilidad de un suelo durante el crecimiento del tubérculo, aceleran el desarrollo fisiológico y la reducción en el período de dormancia.

\section{- Temperatura de almacenamiento}

Las temperaturas altas en el almacenamiento, aceleran el proceso de envejecimiento fisiológico del tubérculo y por consiguiente reducen el período de dormancia, sin embargo; una temperatura fluctuante o un "golpe de frío" de dos a cuatro semanas a bajas temperaturas (debajo de $10^{\circ}$ centigrados) es más efectivo para acortar el período de reposo, que un almacenamiento a una temperatura alta constante.

\section{RESULTADOS DE LA INVESTIGACIÓN}

Los resultados de la investigación se obtuvieron con informantes claves en base en la pregunta siguiente: 
¿Cuáles son las causas que impiden a los productores de papa del departamento de Intibucá acceder a mercados internacionales?

Se identificaron tres aspectos

El primero es la resistencia de los productores de cambiar su forma tradicional o artesanal a la utilización de nuevas tecnologías en el sistema de producción como ser: prácticas de fertilización, selección de la semilla y prácticas fitosanitarias en el cultivo. En este primer aspecto cabe mencionar que nuestro productor se vuelve dependiente, la forma de preparación de los suelos sobre todo porque no se tiene en cuenta un análisis de los tipos de suelo en los cuales se realizan los cultivos

El segundo es la inexistencia de una producción sostenible durante todo el año, ya que su cultura asentada de cultivar es basado en la temporada de invierno y la negativa prevaleciente por su cultura de no estar organizado, lo que genera dificultades para elaborar un plan regional de siembra que garantice un mayor volumen en la producción y poder sobrepasar la demanda de consumo interno y producir un excedente para el mercado externo, lo que generaría otras oportunidades no sólo en tener mejores precios, sino de acceder tecnología de punta y acorde con nuestros suelos.

Y la última es la dependencia de nuestros productores de la semilla importada, al igual que sus agroquímicos e insumos que han tenido un comportamiento a la alza, lo que ha generado por un lado que el productor emigre en busca de otros cultivos de tipo tradicional que no implique mayor esfuerzo e inversión económica, ya que muchas veces para cultivar una hectárea hay que invertir de L. 100,000.00 hasta L.120,000.00 y más. Lo que vuelve
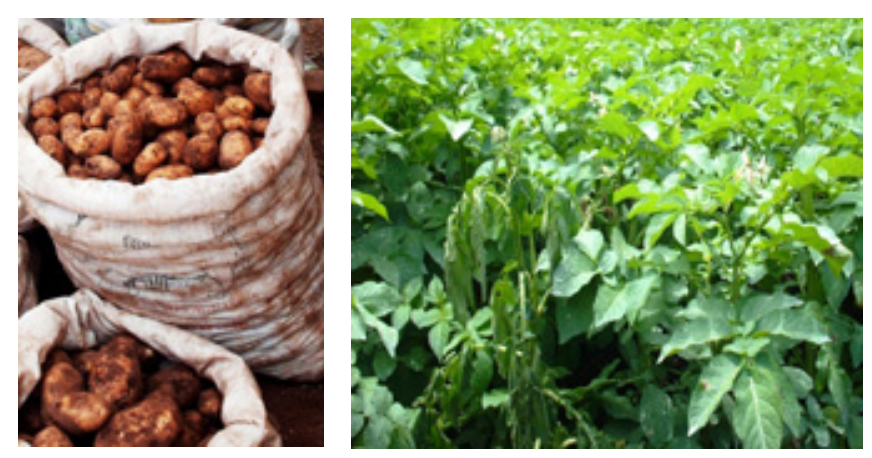

imposible para muchos dedicarse a dicho cultivo, a esto hay que decir que la semilla y los insumos provistos por intermediarios o coyotes no reúnen la calidad deseada, ocasionando desconfianza en los rendimientos y lo peor de todo es que los intermediarios al proporcionar todo lo necesario para la producción, manipulan los precios lo que repercute, al final del ciclo productivo que las ganancias no sean significativas para los productores, obteniendo como resultado en todos los ciclos de siembra que no haya crecimiento en los volúmenes de producción.

Otro de los productores de papa en Intibucá a quién se le pidió que enumerara las limitantes enfrentadas para producir papa en escala y vender fuera del país, comenzó diciendo: no estoy produciendo papa porque he tenido una pérdida de más de L. 160,000.00 y actualmente el costo de producción de un quintal de papa anda en L.450.00 utilizando riego por goteo y proyectado a 30 quintales por tarea o sea 480 quintales por manzana y en el mercado local los coyotes le pagan la carga entre $\mathrm{L}$. 900.00 y L. 1,000.00 más el riesgo que se corre con tanta plaga mejor no producir, sembrar papa tiene un $90 \%$ de probabilidades de pérdida.

Los principales problemas identificados por los productores de papa son:

$\checkmark$ No hay una cuarentena al momento de ingresar en la semilla por los entes del estado encargados del control de calidad

$\checkmark$ Muchas plagas, agua contaminada, semilla dañada y cambios climáticos.

$\checkmark$ Los coyotes o comercializadores de la semilla de papa no le dan la madurez deseada.

$\checkmark$ La llegada de la mosca blanca y plagas nuevas en la zona.

$\checkmark$ Escasez de mano de obra.

$\checkmark$ Falta de organización de los productores y apoyo del la Secretaría de Agricultura y Ganadería / Gobierno para la producción y comercialización.

$\checkmark$ Los costos de los insumos van en alza cada día y se vuelven inaccesibles para los pequeños y medianos productores. 
Las plantas de papa que provienen de semilla fisiológicamente más vieja, tienen las siguientes características con respecto aquellas de semilla joven:

\begin{tabular}{c|c|c|c|}
\hline & \multicolumn{1}{|c|}{ Semilla Vieja } & $\bullet$ & \multicolumn{1}{c}{ Semilla Joven } \\
\hline$\checkmark$ Emergencia más rápida & $\checkmark$ Emergencia tardía \\
\hline$\checkmark$ Tuberización temprana & $\checkmark$ Tuberización tardía \\
\hline$\checkmark$ Mayor número de tallos & $\checkmark$ Menor número de tallos \\
\hline$\checkmark$ Menor desarrollo del follaje & $\checkmark$ Mayor desarrollo del follaje \\
$\checkmark$ & Maduración temprana & $\checkmark$ Maduración tardía \\
\hline$\checkmark$ Rendimiento bajo & $\checkmark$ Rendimiento alto \\
$\checkmark$ Senescencia más temprana & $\checkmark$ Senescencia más tardía \\
\hline
\end{tabular}

Fuente: Elaboración propia en base a entrevistas de campo, 2008

Del cultivo de la papa se derivan una serie de subproductos que la industria procesa como harina de papa, churros, almidón, papas fritas en diversas presentaciones, hojuelas chips, alcoholes y fenoles (biodiessel).

La oferta de papa en Honduras, es relativamente poca lo que puede comprobarse en la Cuadro No. 1, se destacan tres departamentos que tienen potencial y se dedican al cultivo del tubérculo, como se observa en el Gráfico No. 1, Intibucá ocupa el primer lugar en producción, pero se hace la aclaración que en el departamento sólo dos municipios se dedican en mayor escala a la producción y esos municipios son Yamaranguila y el de Intibucá.

El estudio muestra que la oferta de papa en vez de incrementarse tiende a disminuir, por diversos factores que fueron enumeradas por los entrevistados, a pesar de la promoción realizada por el Estado por medio de la Secretaria de Agricultura y Ganadera en el sentido de capitalizar el Banco Nacional de Desarrollo Agrícola

\section{Cuadro No. 1. Fuente: Elaboración propia}

\begin{tabular}{|l|c|c|l|}
\hline \multicolumn{1}{|c|}{ Lugar } & Area & Qq & \multicolumn{1}{|c|}{$\begin{array}{c}\text { Variedades } \\
\text { Sembradas }\end{array}$} \\
\hline Intibucá & 403.4 & 121,020 & $\begin{array}{l}\text { Bellini, ajiba, provento, } \\
\text { derby, arnova, mondial } \\
\text { y caesar. }\end{array}$ \\
\hline La Paz & 277.3 & 97,095 & $\begin{array}{l}\text { Provento, granola, cal } \\
\text { white }\end{array}$ \\
\hline Ocotepeque & 100 & 32,200 & $\begin{array}{l}\text { Provento, granola, cal } \\
\text { white }\end{array}$ \\
\hline
\end{tabular}

Fuente: Elaboración propia

\section{Gráfico No. 1. Producción de papa en occidente}

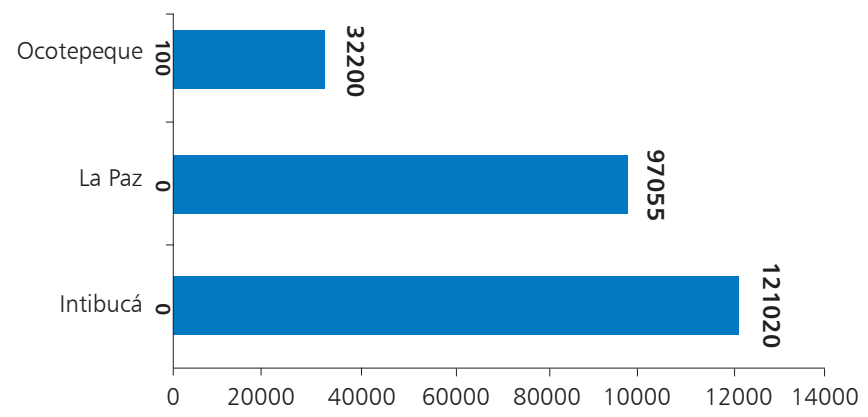

Fuente: Elaboración propia

(BANADESA) los resultados no se han podido observar en el corto plazo, lo que se puede predecir es que los frutos de dichos esfuerzos no serán tan halagadores como los sueña el Estado, ya que no existe una política clara en materia de producción, que garantice la inversión del productor, por los diversos fenómenos climáticos que afectan en la actualidad al país y región.

Es importante mencionar que un resultado de esta investigación de la promoción del Año Internacional de la Papa (AIP) puede dirigir la atención mundial hacia soluciones para intensificar en forma sostenible los sistemas agrícolas y frenar o invertir la pérdida de recursos naturales.

En el caso de Intibucá las plagas que afectan el cultivo de las papa son: gallina ciega (phyllophaga spp.), palomilla de la papa, phthorimaea operculella y tesa solannivora), mosca minadora (liriomyza spp). Las enfermedades más comunes tizón tardío (phythophthora infestans), Tizón temprano (alternaria solani), marchites bacteriana, pudrición blanda o pierna negra (carotovora). Este tipo de enfermedades al no ser contraladas tienen afectar sustancialmente los rendimientos de la cosecha.

\section{METODOLOGÍA}

Para la realización de la presente investigación, se hizo uso de varias fuentes secundarias y primarias, de las 
cuales se tomó los aspectos más relevantes y de interés de tal manera que la investigación fuera atractiva para el lector, la misma llevo mucho tiempo, para efectos de obtener información relevante y que se pudiera comparar con la ya existente, se llevaron a cabo visitas a los productores en sus respectivos centros de trabajo, se realizó recorridos por algunas parcelas con el fin de inspeccionar de forma directa el cultivo, lo que dió como resultado la observación de parcelas dañadas por las plagas, obteniendo un panorama general y específico, así mismo se hizo uso de la técnica de la entrevista directa a productores considerados para efectos de la investigación como informantes claves, aspecto que hace interesante y útil para el lector.

De los datos obtenidos durante todo el proceso se logró extraer lo esencial y de significativo, para que los resultados tengan la utilidad deseada por los interesados en estudiar o conocer sobre el cultivo de la papa en Intibucá.

Las entrevistas con los informantes se escribieron de forma textual, lo que permite cotejar entre la teoría y la práctica versus la realidad actual en cuanto al cultivo en mención. También se construyeron gráficos y tablas que le dan una ilustración sencilla de análisis sobre el tema.

\section{CONCLUSIONES}

1. No cabe duda que la calidad de la semilla juega un papel fundamental que influye en los productores para que estos no siembren papa en forma escalonada y aumente la producción de la misma.

2. El alza de los insumos y la falta de una fijación de precios para la cosecha hace que los productores fracasen sino es por precios es por las plagas.

3. La falta de apoyo por parte del Estado en relación al acceso a semilla de calidad y a buenos precios en la comercialización impide producir volúmenes y calidad.

4. La prisa de los llamados coyotes o intermediarios por alcanzar los buenos precios del mercado no dejan completar el ciclo de la madurez de la papa y la cortan tierna y después hacen caer los precios por la falta de calidad.
5. Sin duda la migración es otro factor determinante, ya que ha causado escasez de mano de obra, impidiendo que los productores puedan ampliar el área de cultivo.

6. La falta de organización de los productores, hace que por temporadas aumenten la producción de papa, sin considerar la demanda del mercado y el costo de los insumos van en alza cada día, limitando a los pequeños y medianos productores a producir pequeñas parcelas, lo que hace bajar los volúmenes de producción.

7. Es importante reconocer que a pesar del potencial productivo de la papa que tiene el departamento en sus sitios más altos de Yamaranguila e Intibucá; en Honduras se consume más de lo que se produce, representando un gran reto para los productores e inversionistas el abastecimiento del mercado local y proyectar un excedente a mercados externos.

8. Al disminuir la superficie de las parcelas, muchas familias de agricultores están dejando de cultivar legumbres para producir raíces y tubérculos a fin de satisfacer sus necesidades de subsistencia e ingresos. Las fincas que se reducen de tamaño se cultivan cada vez con mayor intensidad, lo que erosiona el suelo y crea desequilibrios ecológicos que propician brotes de plagas y enfermedades.

9. Los cambios climáticos en los últimos años que ha experimentado el departamento de Intibucá, ha dado lugar al surgimiento de nuevas plagas como la mosca blanca y la paratiosa.

\section{RECOMENDACIONES}

1. Se debe focalizar en el marco de la política comercial hondureña y con la facilitación del sector público, las acciones privadas en sus distintos niveles, dirigidas a aquellos bienes con una potencial de oferta productiva y exportadora, agregando un valor agregado al producto como parte de la calidad requerida para los productos exportables.

2. Para competir en los mercados regionales y mundiales se necesitan tecnologías que incrementen la producción y economicen insumos, con el fin de contri- 
buir a cerrar la brecha persistente entre la producción y los costos, generando materia prima como parte de los insumos de producción.

3. Se debe apoyar a las poblaciones que representan potenciales productivos, para que puedan adoptar tecnologías apropiadas y apliquen para que obtengan resultados significados en la diversificación agrícola, permitiéndoles varias opciones de ingreso y que puedan elegir con certeza el tipo de cultivo que les dará mayor rendimiento, no sólo en volumen de producción sino en oportunidades de mercado.

4. El Estado debe consensuar con todos los sectores de la sociedad una política en materia de producción, que facilite no sólo la seguridad jurídica de la propiedad, los aranceles de los productos como de la materia prima y un control riguroso de la calidad, a la par de políticas que incentiven al agro en generar una producción a escala y con un encadenamiento en todas sus partes.

5. Penalizar aquellos que se dedican a la especulación, provocando incertidumbre y desánimo en los productores, lo que trae como consecuencia el abandono de la actividad agrícola, en la cual descansa la generación de riqueza y producción de alimentos para la humanidad.

6. Se debe apoyar toda iniciativa en materia de producción, sin atentar con los pocos recursos existentes en materia ambiental, ya que de lo contrario podríamos aumentar la producción de alimentos, pero disminuir nuestros recursos, lo que a futuro ocasionaría otro problema mayor, que atentaría con las generaciones actuales y futuras.
7. El Estado debe asumir su rol que le corresponde como ente regulador de los requisitos de exportación e importación, para evitar que la materia prima importada reúna todos los requisitos requeridos para que el productor no pierda su capital, al invertir en productos de mala calidad y que su producción se vea afectada.

\section{BIBLIOGRAFÍA}

- Alvarado L.F. 1984. Fisiología de la semilla. En curso de producción y Almacenamiento de semilla de papa.

- Asociación de Municipios de Intibucá (2008).

- Bejarano, J L, productor de papa Yamaranguila, Intibucá (2008).

- $\quad$ Encuestas realizadas por el ICTA. (1999).

- Fisiología y manejo de tubérculos - semilla de papa Peña L.A, V1.

- Foro mundial reclama la patata como remedio para mitigar el hambre y la pobreza argenpapa España 28-3-2008.

- Hidalgo, O. 1997. Producción de tubérculos-semilla de papa. Centro Internacional de Papa. 19 p. Lima-Perú.

- Informe de Desarrollo Humano (IDH 2005).

- Informe de Desarrollo Humano (IDH 2006).

- Informe de Desarrollo Humano (IDH 2007).

- Inversiones y Desarrollo de Centroamérica, S.A. Diagnostico de papa Guatemala, Septiembre 1999).

- MSc. Investigador Agrícola Corpoica C.I. Obonuco. E-mail: luisalpena@hotmail.com

- $\quad$ Perfil de mercado semilla de papa-Honduras Pro Chile Tegucigalpa, Agosto 2006.

- $\quad$ SAG Plan de Reactivación Agrícola, 2007.

- Valladares, C, coordinador DICTA/SAG/Intibucá. Hn (2008)

www.faostatic.fao.org/potato2008@fao.org. www.monografias.com/trabajos www.potato2008/org/es/mundo/america_latina www.sag.gob.hn//SAG/DICTA 


\section{Anexo No. 1 \\ Declaración de la ONU \\ Año Internacional de la Papa}

La asamblea general,

- Observando que la papa es un alimento básico de la dieta de la población mundial.

- Recordando la resolución 4/2005 de la Conferencia de la Organización de las Naciones Unidas para la Agricultura y la Alimentación, aprobada el 25 de noviembre de 2005.

- Afirmando la necesidad de concentrar la atención mundial en la función que puede desempeñar la papa en la consecución de la seguridad alimentaria y la erradicación de la pobreza para apoyar el logro de los objetivos de desarrollo acordados internacionalmente, incluidos los Objetivos del Desarrollo del Milenio.

1. Declarar 2008 Año Internacional de la Papa;

2. Invita a la Organización de las Naciones Unidas para la Agricultura y la Alimentación a facilitar la observancia del Año Internacional de la Papa, en colaboración con los gobiernos, el Programa de las Naciones Unidas para el Desarrollo, los centros del Grupo Consultivo sobre Investigaciones Agrícolas Internacionales y otras organizaciones competentes del sistema de las Naciones Unidas, así como las organizaciones no gubernamentales pertinentes.

22 de diciembre de 2005 


\author{
Anexo No. 2 \\ Resolución de la FAO \\ Año Internacional de la Papa
}

La conferencia

- Tomando nota de que la papa es un alimento básico de la dieta de la población mundial;

- Deseando centrar la atención mundial en la función que puede desempeñar la papa para proporcionar seguridad alimentaria y aliviar la pobreza de la población;

- Convencida de que deben dirigirse esfuerzos concertados a abordar las cuestiones y desafíos que se derivan de los problemas de la reducción de la productividad, el agotamiento de los recursos naturales y los problemas del medio ambiente, así como de las pérdidas de biodiversidad en los actuales sistemas de producción de la papa;

- Reconociendo que hay una asociación importante entre las instituciones dedicadas a la investigación y el desarrollo de la papa;

- Recordando asimismo que, durante su $31^{\circ}$ período de sesiones, aprobó el Tratado Internacional sobre los Recursos Filogenéticos para la Alimentación y la Agricultura;

- Afirmando la necesidad de reavivar la sensibilidad del público respecto a la relación que existe entre la pobreza, la seguridad alimentaria, la malnutrición y el aporte que la papa puede brindar para vencer al hambre:

Pide al Director General que transmita esta Resolución al Secretario General de las Naciones Unidas con miras a que las Naciones Unidas declaren el año 2008 como el Año Internacional de la Papa. Pide asimismo al Director General que presente informes sobre la marcha de los trabajos a la Conferencia en futuros períodos de sesiones y al Secretario General de las Naciones Unidas acerca de las medidas que se tomen para el Año Internacional de las Papa, incluidos los recursos financieros obtenidos, así como sobre los resultados del Año, una vez concluido el mismo.

25 de noviembre de 2005 